\title{
Doped Graphene as Non-Metallic Catalyst for Fuel Cells
}

\author{
Adriana MARINOIU *, Mircea RACEANU, Elena CARCADEA, Mihai VARLAM, \\ Amalia SOARE, Ioan STEFANESCU
}

\author{
National Research and Development Institute for Cryogenics and Isotopic Technologies - ICSI Rm. Valcea, Uzinei Street \\ no. 4, P.O. Box Râureni 7, 240050, Râmnicu Vâlcea, Romania \\ cross $^{\text {ref }}$ http://dx.doi.org/10.5755/j01.ms.23.2.16216
}

Received 08 September 2016; accepted 04 November 2016

\begin{abstract}
Aiming a commercial development of proton exchange membrane fuel cells (PEMFC), a low cost, sustainable and high performance electrocatalyst for oxygen reduction reaction (ORR) with capability to replace/reduce rare metals, are high desirable. In this paper, we present a class of doped graphene, namely iodinated graphene with highly ORR electrochemical performances, synthesized by using the electrophilic substitution method. The prepared samples were characterized by different techniques, including Scanning Electron Microscopy SEM, X-ray photoelectron spectroscopy XPS, Raman spectroscopy, surface area measurement by BET method, that revealed the structure and morphology. The most highly iodinated graphene was tested in a single cell by measuring the cyclic voltammetry. The electrochemical performances were evaluated and compared with a typical PEMFC configuration, when a single cathodic peak at $0.2 \mathrm{~V}$ with a current density of $-3.67 \mathrm{~mA} \mathrm{~cm}^{-2}$ for the $\mathrm{Pt} / \mathrm{C}$ electrode was obtained. The best electrochemical performances in terms of electrochemical active area, was obtained for a new concept of cathode composed from $\mathrm{Pt} / \mathrm{C}$ - iodine doped graphene, when a well-defined peak centred at $0.23 \mathrm{~V}$ with a current density of approx. $-9.1 \mathrm{~mA} \mathrm{~cm}^{-2}$ was obtained, indicating a high catalytic activity for ORR.
\end{abstract}

Keywords: iodine doped graphene, catalyst, fuel cell, electrophilic substitution.

\section{INTRODUCTION}

Proton exchange membrane fuel cells (PEMFCs) have attracted a considerable attention as clean and efficient power sources. Up until the present day, platinum and platinum-based composites have been considered as the most efficient catalysts, due to its remarkable electrochemical performances. However, a large scale application is conditioned by its drawbacks, besides its high cost, $\mathrm{CO}$ poisoning effect, lack of stability. There is an important trend to replace the Pt-based oxygen reduction reaction (ORR) electrocatalysts with metal-free electrocatalysts having high catalytic activity and durability in a sustainable effort to diminish the FC production cost and allow this technology to become approachable for commercialization [1-4].

Since the single-layer graphene was discovered, this research area has attracted great interest because the improved performances as catalytic support in FC were demonstrated [5-8]. Recently, graphenes doped with heteroatom, such as boron $(\mathrm{B})$, halogen $(\mathrm{Cl}, \mathrm{Br}, \mathrm{I})$, nitrogen $(\mathrm{N})$, phosphorus $(\mathrm{P})$, sulphur $(\mathrm{S})$, and their mixtures, have attracted attentions as metal-free ORR electrocatalysts, based on different electronegativity between the heteroatom dopants [9-16].

The remarkably improved catalytic performance of halogenated doped graphene was assigned to the electronaccepting ability of the chemically-bonded atoms, by creating of positive charge on adjoining conjugated carbon atoms in order to facilitate the chemical adsorption of oxygen and as consequence favouring the oxygen

\footnotetext{
* Corresponding author. Tel.: +40250 732744; fax: +40250 732746 .

E-mail address: adriana.marinoiu@icsi.ro (A. Marinoiu)
}

reduction reaction (ORR). Starting from the supposition that it is essential to incorporate halogen covalentlybonded atoms into the graphene structure in order to generate intermolecular charge-transfer, the low cost chemical processes for the preparation of doped graphenes are necessary for the realistic commercial applications. It is important to note that the common routes such as chemical vapour deposition (CVD) and/or Hummer's method for obtaining of doped graphene are quite expensive, involve environmental hazard reagents, making those methods improper for a large scale production [17-26].

In this study we will use the previous protocol that we developed for synthesis of graphene base materials [25] in order to prepare iodine doped graphenes (IDG), followed by their testing and validation as base materials for FC electrodes.

The work reveals the developing of a new concept of cathode electrodes for FC, starting from up-to-date design of catalyst based on non-noble metal. A correlation between composition, morphology and ORR activity could offer a better understanding regarding the nature of active sites in different iodinated graphenes. We hypothesize that the ORR activity could be improved due to electrocatalytic efficiency of iodine doping, facilitated by forming charge transfer complexes of $\mathrm{I}_{3}{ }^{-}$and $\mathrm{I}_{5}{ }^{-}$, which enhance the doping capability and graphene work function [16,17]. For comparison, the diagnostic experiments with nanostructured electrocatalytic systems utilizing Pt noble metal, at the lowest possible loadings, are going to be explored in order to permit their high practical utility. Due to the fact that the experimental information connected to the electrochemical science and technology of ORR for iodinated graphenes is not yet well explained, any achievements regarding these electrocatalytic systems 
providing good ORR performances could be primary importance.

\section{EXPERIMENTAL}

A direct iodinated method was used for preparation of iodine doped graphene materials (IDG), based on electrophilic substitution. All chemicals were of analytical grade and used without additional processing. Graphene (Gr) is iodinated by the direct method using the system $\mathrm{KI} / \mathrm{NaIO}_{4}$ at the molar ratio $\mathrm{I}^{+} / \mathrm{Gr}=1 . \mathrm{H}_{2} \mathrm{SO}_{4}$ min. $95 \%$ wt. was introduced at room temperature, in a round 5-neck round flask of $1000 \mathrm{ml}$, thermostated in glycerine bath and equipped with mechanical stirrer with tight guide KPG, thermometer, air-cooled reflux condenser and drying tube. Under continuously stirring are inserted in small portions: $\mathrm{NaIO}_{4}$ and finely milled KI. The mixture is stirred $30 \mathrm{~min}$ at $\max 35^{\circ} \mathrm{C}$. Then $2 \mathrm{~g}$ graphene $\mathrm{xGnP}$ of commercial type (XG Graphene Nanoplateles Science, grade M, specific surface area $105 \mathrm{~m}^{2} / \mathrm{g}$ ) is added to the reaction mass and stirred for 24 hours at $30-35{ }^{\circ} \mathrm{C}$. The reaction mass is stirred gently, transferred into a beaker of $3000 \mathrm{ml}$ and cooled externally with ice. The obtained solid is washed 3 times by decantation, separated by settling and filtration, washed filter to free $\mathrm{SO}_{4}{ }^{2}$, and dried at $50{ }^{\circ} \mathrm{C}$ and 0.5 atm in an oven, then in a vacuum desiccator to constant weight (it takes several days due to high elementary iodine content). Approximately $2 \mathrm{~g}$ of solid is obtained. For a totally separation of elemental iodine, the solid product was introduced in a cartridge paper and extracted in a Soxhlet extractor with acetone until the extract is colourless. After drying to constant mass at $50^{\circ} \mathrm{C}$ there were obtained a solid product encoded IDG_1. The same protocol was followed for IDG_2 synthesis except that the starting raw material was single layer graphene powder (specific surface area $750 \mathrm{~m}^{2} / \mathrm{g}$, ACS Material, USA). The specific surface areas of initial and prepared samples were determined using the BET method (Brunauer-EmmettTeller theory for surface area) by performing nitrogen sorption measurements using a Quantachrome Autosorb IQ equipment. The nitrogen adsorption-desorption measurements were also used to study the porous features of the catalysts. The adsorption and desorption experiments were done at $77 \mathrm{~K}$ after initial pre-treatment of the samples by degassing at $115^{\circ} \mathrm{C}$ for 4 hours. Fourier transform infrared (FT-IR) spectra were recorded in this study on a NICOLET IMPACT 410 Fourier Transform Infrared spectrophotometer. Surface analysis performed by X-Ray Photoelectron Spectroscopy (XPS) was carried out on a Quantera SXM equipment, with a base pressure in the analysis chamber of $10^{-9}$ Torr. The X-ray source was $\mathrm{Al} \mathrm{K}$ radiation (1486.6eV, monochromatized) and the overall energy resolution is estimated at $0.65 \mathrm{eV}$ by the full width at half maximum (FWHM) of the $\mathrm{Au} 4 \mathrm{f}_{7 / 2}$ line. In order to take into account; the charging effect on the measured Binding Energies (BEs), the spectra were calibrated using the $\mathrm{C} 1 \mathrm{~s}$ line $(\mathrm{BE}=284.8 \mathrm{eV}, \mathrm{C}-\mathrm{C}(\mathrm{CH}) \mathrm{n}$ bond $)$ of the adsorbed hydrocarbon on the sample surface. A dual beam neutralizing procedure ( $\mathrm{e}^{-}$and $\mathrm{Ar}^{+}$ion beams) has been used to compensate the charging effect in insulating samples. Scanning electron microscopy was performed using a Karl Zeiss SIGMA Variable Pressure Field Emission Scanning Electron Microscope.

A single cell system with an active area of $5 \mathrm{~cm}^{2}$ was used for electrochemical performances to test the prepared catalysts. Several steps have been carried out for manufacturing each PEMFC. First, a catalytic ink containing catalyst was prepared by ultrasonically mixing of catalyst powder, isopropanol, Nafion ionomer solution $5 \mathrm{wt} . \%$. (Dupont, USA) for 2 hours. The ink was afterwards sprayed (using SonoTek, USA) on each side of the pre-treated membrane (Nafion Dupont, USA). $0.2 \mathrm{mg} / \mathrm{cm}^{2}$ Pt loading was used for anode side of the fuel cell developed, based on a commercial Hispec 4000 Pt/C catalyst (Alfa Aesar, USA). The cathode catalyst layer was modified taking into account $0.2 \mathrm{mg} / \mathrm{cm}^{2} \mathrm{Pt}$ loading as a recommended up to date value for Pt loading and a similar iodine loading, resulting in 2 configurations: (1): $0.2 \mathrm{mg} / \mathrm{cm}^{2}$ Pt loading sprayed on Nafion membrane, (2) $0.2 \mathrm{mg} / \mathrm{cm}^{2} \mathrm{Pt}$ loadings sprayed on membrane $+0.2 \mathrm{mg} / \mathrm{cm}^{2}$ iodine loading sprayed on gas diffusion layer (GDL). The prepared MEA and GDL layers from both sides (anode-cathode) were pressed at $300 \mathrm{kgf}$, $125^{\circ} \mathrm{C}$ for $2 \mathrm{~min}$, and then was assembled in a single $5 \mathrm{~cm}^{2}$ cell system. Cyclic voltammetry plots were recorded using a homemade test station, which includes: electrochemical workstation (PARSTAT 2273), fuel cell (ElectroChem, USA), DS electronic load (AMETEK Sorensen SLH 60V/120A 600W), humidifier (ARBIN DPHS 10, USA). $\mathrm{H}_{2}$ and air were used as fuel and oxidant and the following operating conditions were used: $\mathrm{H}_{2}$ flow rate: $100 \mathrm{ml} \mathrm{min}^{-1}$,

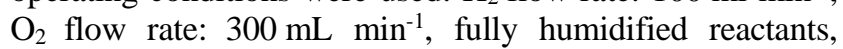
temperature $60^{\circ} \mathrm{C}, 1$ bar pressure.

\section{RESULTS AND DISCUSSION}

Iodine-doped graphenes have been successfully obtained by a simple and low cost strategy based on electrophilic substitution. First, the characterization of the prepared materials was performed in order to elaborate the structural quality and to confirm the assumption about the iodine doping, by BET method. The $\mathrm{N}_{2}$ adsorptiondesorption isotherms for prepared iodinated graphene show characteristics of type IV (Fig. 1, Fig. 2). In accordance with that type, a strong $\mathrm{N}_{2}$ adsorption uptake at lower relative pressure, indicates the existence of numerous micropores in samples. Also, an abrupt increase at high relative pressure with hysteresis is assigned to the presence of mesopores. The BET surface areas were estimated of $45 \mathrm{~m}^{2} \mathrm{~g}^{-1}$ (corresponding to IDG_1 and respectively $320 \mathrm{~m}^{2} \mathrm{~g}^{-1}$ for IDG_2).

The obtained BET surface area of prepared iodinated graphene indicates a decrease of specific surface area during the proposed technologies. The maximum value for surface area $\left(320 \mathrm{~m}^{2} \mathrm{~g}^{-1}\right)$ is bellow than our previous obtained results in the case of graphene sheets $\left(795 \mathrm{~m}^{2} \mathrm{~g}^{-1}\right)$ [25] or to surface area of commercial starting graphene (XGrN Science with $100 \mathrm{~m}^{2} \mathrm{~g}^{-1}$ used for IDG_1 preparation and ACS Material type with $750 \mathrm{~m}^{2} \mathrm{~g}^{-1}$ used for IDG_2). However, these finally mentioned values are referring to the reduced graphene sheets, while our current measured surface areas of obtained iodinated graphene samples are consistent with the stacking structure and agglomerated morphology of the doped graphene sheets. 
Supplementary, the pore size distribution was further investigated as an inserted plot. The analysis of pore size distribution also confirmed the coexistence of micro and mesopores, providing a hierarchical porous structure in prepared doped graphene. The hierarchical structure recommends iodine doped graphene as a very promising candidate catalyst for ORR, because of their advantages in the exposure of active sites (the role of micropores) and in the accommodation of reactive molecules shortening the diffusion pathways (the role of mesopores).

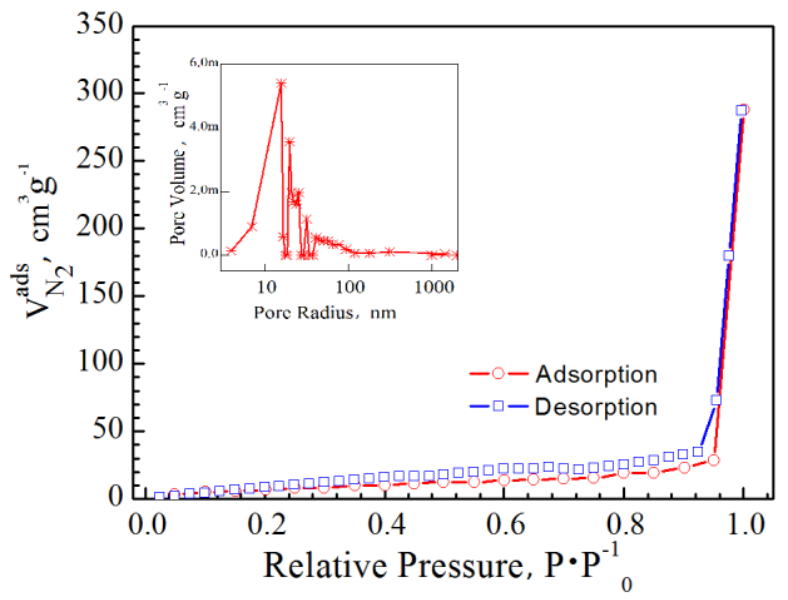

Fig. 1. The adsorption-desorption isotherms for IDG_1

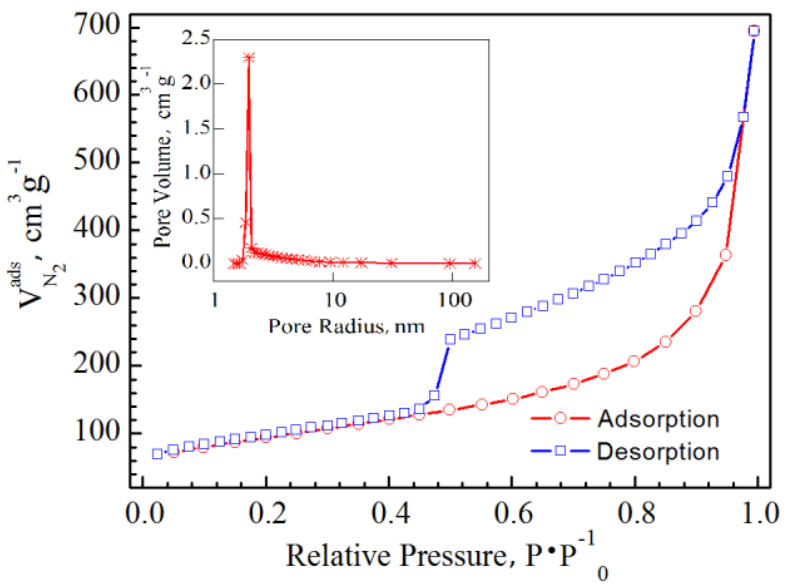

Fig. 2. The adsorption-desorption isotherms for IDG_1

The Scanning Electron Microscopy SEM (Fig. 3, Fig. 4) images illustrate an obvious size reduction of some crystallite sheets from a large initial size of approx. $10 \mu \mathrm{m}$ corresponding to the pristine graphene from XGSience and respectively approx. $5 \mu \mathrm{m}$ corresponding to the graphene from ACS Material, to a smaller crystallite size for both prepared IDG. The size decreasing implies C-C bonds breaking into graphene structures, most probably during exfoliation process, which allows in consequence, the formation of active carbon species to react with iodine.

Fig. 5 presents the FT-IR spectra for the prepared samples. FTIR spectra obtained in transmission mode have shown that iodine doped graphene exhibits much stronger IR bands than graphene. Reference spectrum from the top of figure illustrates the pristine graphene as an almost linear diagram. The other two signals correspond to prepared iodine doped materials and significant changes took place during experimental procedures.

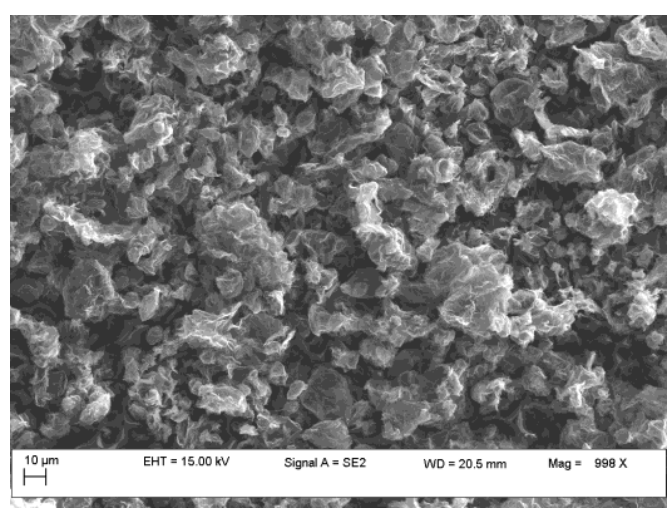

Fig. 3. SEM analysis of prepared IDG_1

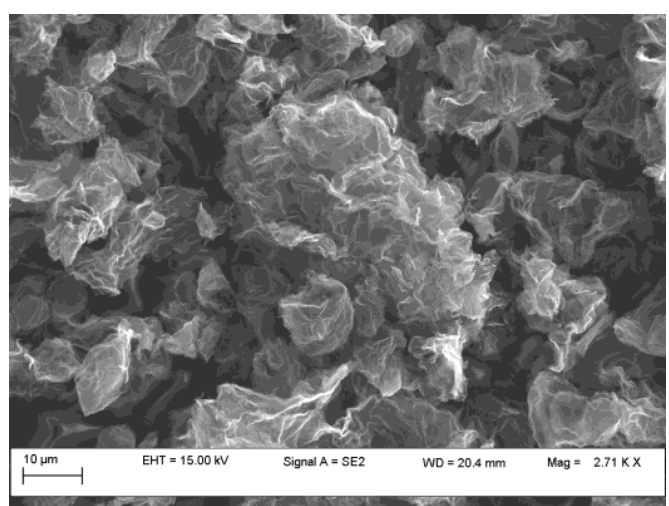

Fig. 4. SEM analysis of prepared IDG_2

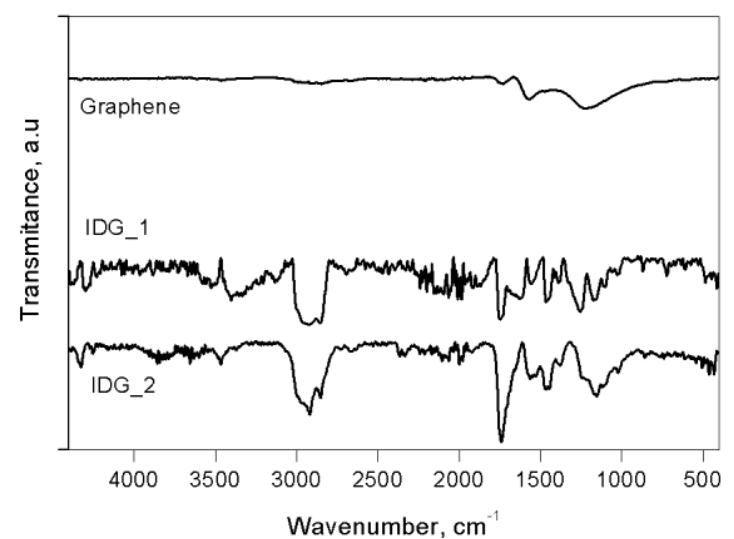

Fig. 5. FT-IR spectra for pristine graphene and iodinated graphenes

The main corresponding bands are: a stretching vibration peak of $\mathrm{C}-\mathrm{I}$ is observed at $725 \mathrm{~cm}^{-1}$; a broad signal between 1100 and $1250 \mathrm{~cm}^{-1}$ is attributed to the oxygen functionalities; carbon atoms of the specific graphene layer is observed at $1590 \mathrm{~cm}^{-1}$; stretching vibration peaks of $\mathrm{C}=\mathrm{C}$ (aromatic) and $\mathrm{C}-\mathrm{O}$ are observed at $1611 \mathrm{~cm}^{-1}$ and $1723 \mathrm{~cm}^{-1}$, respectively; a signal including the peaks of 2850 and $2920 \mathrm{~cm}^{-1}$ is attributed to the $\mathrm{C}-\mathrm{H}$ deformation vibration; hydroxyl groups is located at $3650 \mathrm{~cm}^{-1}$. We have to mention the presence of feature peak at approx. $725 \mathrm{~cm}^{-1}$ which is absent in pristine graphene, but it is present in both doped graphenes, indicating a characteristic $\mathrm{C}-\mathrm{I}$ stretching vibration, confirming the iodine presence. This agrees with the observations of Simek et al. for the iodination of graphite oxide as starting material for flame-retardant additives 
[27]. In this case, the authors also were able to identify the band at $725 \mathrm{~cm}^{-1}$ assigned to $\mathrm{C}-\mathrm{I}$ presence. Moreover, the conclusion was that although the prepared iodinated graphenes were structurally similar, the materials had remarkably different concentrations of iodine. Our FTIR spectra on IDG_1 characterized by increased iodine content have revealed an absorption band much stronger than in IDG_2 case.

X-ray photoelectron spectroscopy (XPS) was performed in order to identify the chemical elements content. The general spectra reveal in Fig. 6 the existing elements on the surface of the samples, namely carbon, oxygen and iodine. Depending on the starting material, iodine has a different doping amount in prepared IDG (Table 1). C1s and O1s signals can be easily observed in prepared doped graphene.

Table 1. Element relative concentrations (wt.\%)

\begin{tabular}{|c|c|c|c|}
\hline \multirow{2}{*}{ Sample } & \multicolumn{4}{|c|}{$\begin{array}{r}\text { The XPS transitions used for quantification } \\
\text { Element relative conc. (wt. \%) }\end{array}$} \\
\cline { 2 - 4 } & C1s & O1s & I3d5 \\
\hline IDG_1 & 86.4 & 6.8 & 6.8 \\
\hline IDG_2 & 89.1 & 8.6 & 2.3 \\
\hline
\end{tabular}

XPS survey spectra for representative sample (highest iodine content) prepared by electrophilic substitution are shown separately below (Fig. 6) For IDG_1 and IDG_2 samples, I3d signal was detected in their curves besides $\mathrm{C} 1 \mathrm{~s}$ and $\mathrm{O} 1 \mathrm{~s}$, indicating that the iodine element has indeed been doped in graphene sheets via the mentioned procedures. The predominant $\mathrm{C} 1 \mathrm{~s}$ peak was found at $284.5 \mathrm{eV}$ binding energy, the $\mathrm{O} 1 \mathrm{~s}$ at $532 \mathrm{eV}$ and the $\mathrm{I} 3 \mathrm{~d}$ peaks at 620 and $631.8 \mathrm{eV}$. The iodine content in the IDG_2 is about $2.3 \mathrm{wt} . \%$, while that of IDG_1 is about 6.8 wt.\%, indicating that the electrophilic substitution is proper synthesis route for introducing the iodine into graphene base material. Accordingly, to assumptions of Hassan et al., the performance of ORR strongly depends on the bonding configuration of the iodine atoms in graphene materials, being known the fact that iodinated materials could promote a high catalytic activity of the carbon materials [28].

The peak deconvolution of iodine suggests that $\mathrm{I}_{3} \mathrm{~d}_{5 / 2}$ appears as two split peaks (620 and $631.8 \mathrm{eV}$ ) which can be attributed to tri-iodide $\left(\mathrm{I}_{3}^{-}\right)$and penta-iodide $\left(\mathrm{I}_{5}^{-}\right)$, respectively.

Iodinated graphene samples were included and tested in a singular PEMFC. We further investigated the electrocatalytic activities of commercial Pt/C catalyst Hispec 4000 as reference electrocatalyst (Fig. 7) and a proposed ORR cathode composed from $\mathrm{Pt} / \mathrm{C}$ and iodine doped graphene (Fig. 8). In order to manufacture the ORR hybrid electrocatalyst, the $\mathrm{Pt} / \mathrm{C}$ was deposited on Nafion membrane and the iodinated graphene was sprayed on gas diffusion layer (GDL). We took into account the IDG_1 as material with higher iodine content.

Cyclic voltammetry (CV) curves were obtained in order to demonstrate the efficient electrochemical activity for ORR in two situations: a) cathode composed from commercial $\mathrm{Pt} / \mathrm{C} 0.2 \mathrm{mg} / \mathrm{cm}^{2}$; b) cathode composed from $\mathrm{Pt} / \mathrm{C}$ and IDG_1. Figure 7 shows a single cathodic peak at
$0.2 \mathrm{~V}$ with a current density of $-3.67 \mathrm{~mA} \mathrm{~cm}^{-2}$ for the $\mathrm{Pt} / \mathrm{C}$ electrode.

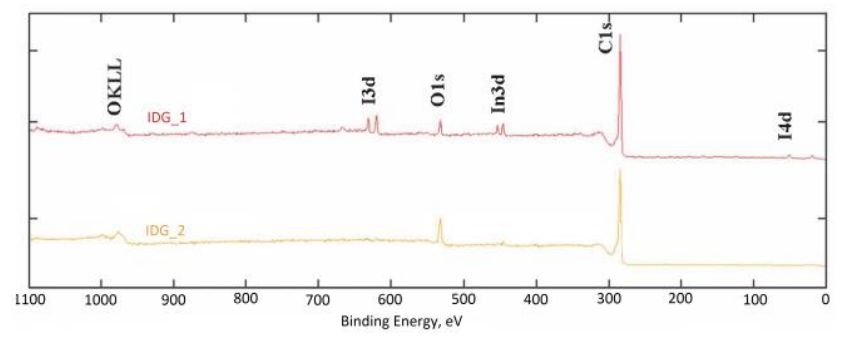

a

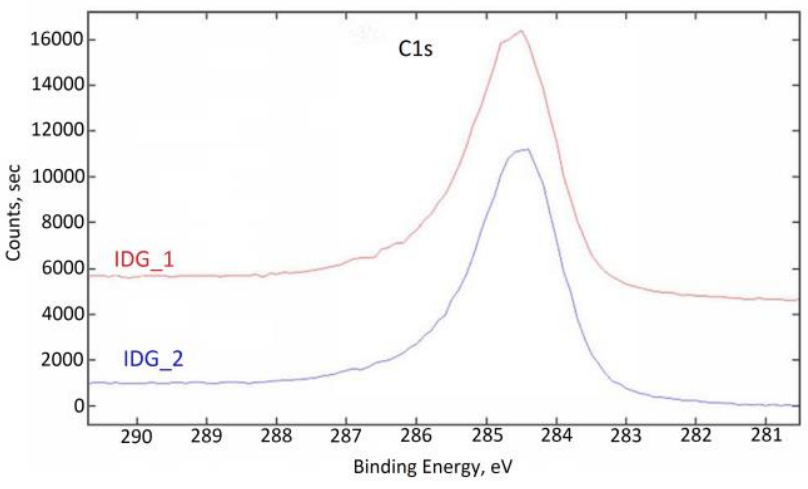

$\mathrm{b}$

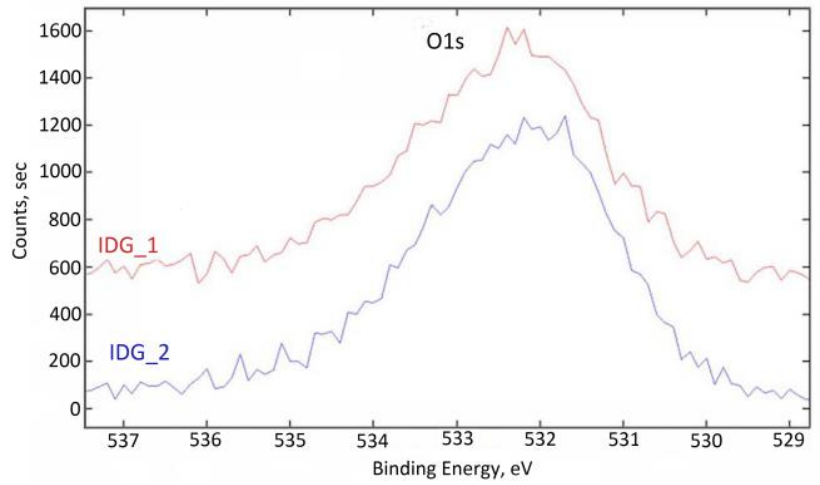

c

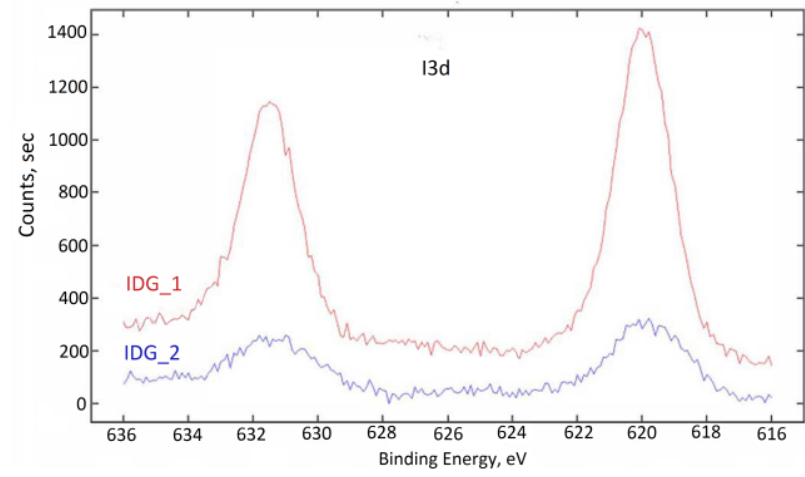

d

Fig. 6. XPS general spectra of iodinated graphene: a-IDG_1 and IDG_2: b-C1s XPS spectra; c-O1s XPS spectra (c); dI 3d XPS spectra

Experimental conditions: the air in the original FC cathode was replaced with $\mathrm{N}_{2}$, potential scan rate: $50 \mathrm{mV} / \mathrm{s}$, temperature $60{ }^{\circ} \mathrm{C}$. 
The corresponding cathodic reduction peak for hybrid cathode $\mathrm{Pt} / \mathrm{C}$ - iodine doped graphene was positively shifted. It is clearly observed a well-defined peak centred at $0.23 \mathrm{~V}$ with a current density of approx. $-9.1 \mathrm{~mA} \mathrm{~cm}^{-2}$, indicating that IDG_1 has a very high catalytic activity for ORR in comparison to the reference cathode (Fig. 8). These values for hybrid cathode are over 2 times that of $\mathrm{Pt} / \mathrm{C}$. The explanation of ORR activity enhancement over iodine doped graphene could be attributed to the higher electronegativity of the iodine $(\chi=2.66)$ than carbon $(\chi=2.55)$, which favourites the polarization of adjacent carbon atoms in graphene framework facilitating as consequence a better $\mathrm{O}_{2}$ adsorption and charge transfer phenomenon.

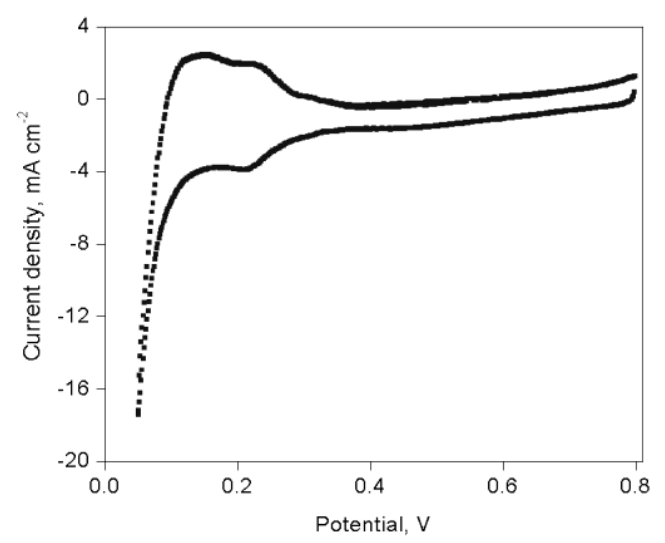

Fig. 7. Cyclic voltammetry performed on in situ FC measurements on cathode electrodes: $\mathrm{Pt} / \mathrm{C} 0.2 \mathrm{mg} / \mathrm{cm}^{2}$

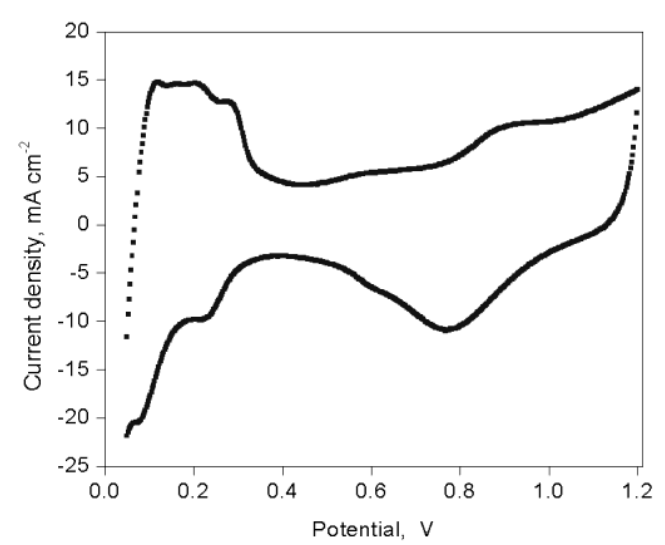

Fig. 8. Cyclic voltammetry performed on in situ FC measurements on cathode electrodes: $\mathrm{Pt} / \mathrm{C} 0.2 \mathrm{mg} / \mathrm{cm}^{2}+$ IDG_1 $0.2 \mathrm{mg} / \mathrm{cm}^{2}$

\section{CONCLUSIONS}

A facile synthesis procedure was devised to obtain iodine doped graphene by electrophilic substitution. The samples were characterized and tested as cathode electrocatalyst for PEMFC. Compared to commercial Pt/C electrocatalyst, a hybrid cathode containing $\mathrm{Pt} / \mathrm{C}$ and iodine doped graphene exhibited a current density twice as high. This behaviour was attributed to a better access of oxygen to Pt sites, based on a higher electronegativity of the iodine than carbon. The study indicates a promising electrocatalyst for PEMFC, which suggest the possibility of replacing actual electrocatalysts based on demonstrated performances.

\section{Acknowledgments}

This work is supported by the National Agency of Scientific Research from Romania by the National Plan of R \& D, Project No. 16360102 and by the Romanian partnership in priority domains-PNII Programme, from MEN-UEFISCDI, under the project no 284/2014.

\section{REFERENCES}

1. Dubau, L., Castanheira, L., Maillard, F., Chatenet, M., Lottin, O., Maranzana, G., Dillet, J., Lamibrac, A., Perrin, J.C., Moukheiber, E., $\quad$ ElKaddouri, A., De Moor, G., Bas, C., Flandin, L., Caqué, N. A Review of PEM Fuel Cell Durability: Materials Degradation, Local Heterogeneities of Aging and Possible Mitigation Strategies Energy and Environment 3 (6) 2014: pp. 540-560.

2. Ahluwalia, R., Wang, $\mathbf{X}$. Fuel Cell Systems for Transportation: Status and Trends Journal of Power Sources 177 2008: pp. $167-176$. https://doi.org/10.1016/j.jpowsour.2007.10.026

3. He, C., Desai, S., Brown, G., Bollepalli, S. PEM Fuel Cell Catalysts: Cost, Performance and Durability Electrochemical Society Interface 2005: pp. 41-44.

4. Oliver, T.H., Joseph, W.S. The Role of Platinum in Proton Exchange Membrane Fuel Cells-Evaluation of Platinum's Unique Properties for Use in Both the Anode and Cathode of a Proton Exchange Membrane Fuel Cell Platinum Metals Review 57 (4) 2013: pp. 259-271.

5. Ji, X., Zhang, X, Zhang, X. Three-Dimensional GrapheneBased Nanomaterials as Electrocatalysts for Oxygen Reduction Reaction Journal of Nanomaterials Article ID 357196, 2015. https://doi.org/10.1155/2015/357196

6. Marinoiu, A., Cobzaru, C., Carcadea, E., Raceanu, M., Atkinson, I., Varlam, M., Stefanescu, I. An Experimental approach for Finding Low Cost Alternative Support Material in PEM Fuel Cells Revue Roumaine de Chimie 61(4-5) 2016: pp. $433-440$

7. Wu, H., Wexler, D., Liu, H. Durability Investigation of Graphene-Supported Pt Nanocatalysts for PEM Fuel Cells Journal of Solid State Electrochemistry 15 2011: pp. $1057-1062$. https://doi.org/10.1007/s10008-011-1317-8

8. Marinoiu, A.,Teodorescu, C., Carcadea, E., Raceanu, M., Varlam, M., Cobzaru, C., Stefanescu, I. Graphene-Based Materials Used as The Catalyst Support for PEMFC Applications Materials Today: Proceedings 2 (6) 2015: pp. $3797-3805$.

9. Sun, X., Song, P., Zhang, Y., Liu, C., Xu, W., Xing, W. A Class of High Performance Metal-Free Oxygen Reduction Electrocatalysts Based on Cheap Carbon Blacks Scientific Report 3 2013: pp. 2505.

10. Ren, G., Lu, X., Li, Y., Zhu, Y., Dai, L., Jiang, L. Porous core-shell $\mathrm{Fe}_{3} \mathrm{C}$ Embedded N-Doped Carbon Nanofibers as an Effective Electrocatalysts for Oxygen Reduction Reaction ACS Applied Materials \& Interfaces 8 (6) 2016: pp. $4118-4125$.

11. Wang, S., Yu, D., Dai, L., Chang, D.W., Baek, J. Polyelectrolyte-Functionalized Graphene as Metal-Free Electrocatalysts for Oxygen Reduction ACS Nano 5 2011: pp. $6202-6209$. 
12. Lee, K., Zhang, J., Wang, H., Wilkinson, D. Progress in the Synthesis of Carbon Nanotube- And NanofiberSupported Pt Electrocatalysts for PEM Fuel Cell Catalysis Journal of Applied Electrochemistry 36 2006: pp. $507-522$. https://doi.org/10.1007/s10800-006-9120-4

13. Serp, P., Corrias, M., Kalck, P. Carbon Nanotubes and Nanofibers in Catalysis Applied Catalysis A 253 2003: pp. $337-358$.

14. Lau, C., Cervini, R., Clarke, S., Markovic, M., Matisons, J., Hawkins, S., Huynh, C., Simon, G. The Effect of Functionalization on Structure and Electrical Conductivity of Multi-Walled Carbon Nanotubes Journal of Nanoparticle Research 10 2008: pp. 77-88. https://doi.org/10.1007/s11051-008-9376-1

15. Peng, H., Mo, Z., Liao, S., Liang, H., Yang, L., Luo, F., Song, H., Zhong, Y., Zhang, B. High Performance Fe-and N-Doped Carbon Catalyst with Graphene Structure for Oxygen Reduction Scientific Reports 3 2013: pp. 1765.

16. Zhan, Y., Huang, J., Lin, Z., Yu, X., Zeng, D., Zhang, X., Xie, F., Zhang, W., Chen, J., Meng, H. Iodine/Nitrogen Co-Doped Graphene as Metal Free Catalyst for Oxygen Reduction Reaction Carbon 95 2015: pp. 930-939.

17. Poh, H.L., Šimek, P., Sofer, Z., Pumera, M. Halogenation of Graphene with Chlorine, Bromine, or Iodine in a Halogen Atmosphere Chemistry a European Journal 19 2013: pp. 2655-2662.

18. Jeon, I.Y., Choi, H.J., Choi, M., Seo, J.M., Jung, S.M., Kim, M.J., Zhang, S., Zhang, L., Xia, Z., Dai, L., Park, N., Baek, J.B. Facile, Scalable Synthesis of EdgeHalogenated Graphene Nanoplatelets as Efficient Metal-Free Eletrocatalysts for Oxygen Reduction Reaction Scientific Reports 3 2013: pp. 1810.

19. Wang, B. Recent Development of Non-Platinum Catalysts for Oxygen Reduction Reaction Journal of Power Sources 152 2005: pp. 1-15.

20. Fazio, G., Ferrighi, L., Valentin, C.D. Boron-Doped Graphene as Active Electrocatalyst for Oxygen Reduction Reaction at a Fuel-Cell Cathode Journal of Catalysis 318 2014: pp. 203-210. https://doi.org/10.1016/j.jcat.2014.07.024

21. Zhang, L., Niu, J., Li, M., Xia, Z. Catalytic Mechanisms of Sulfur-Doped Graphene as Efficient Oxygen Reduction Reaction Catalysts for Fuel Cells Journal of Physical Chemistry C 118 (7) 2014: pp. 3545-3553.

22. Xu, X., Yuan, T., Zhou, Y., Li, Y., Lu, J., Tian, X., Wang, D., Wang, J. Facile Synthesis of Boron and Nitrogen-Doped Graphene as Efficient Electrocatalyst for the Oxygen Reduction Reaction in Alkaline Media International Journal of Hydrogen Energy 39 (28) 2014: pp. $16043-16052$.

23. Shui, J., Wang, M., Du, F., Dai, L. N-doped Carbon Nanomaterials Are Durable Catalysts for Oxygen Reduction Reaction in Acidic Fuel Cells Science Advances 1 (1) 2015: e1400129.

24. Qu, L., Liu, Y., Baek, J.B., Dai, L. Nitrogen-Doped Graphene as Efficient Metal-Free Electrocatalyst for Oxygen Reduction in Fuel Cells ACS Nano 4 (3) 2010: pp. $1321-1326$.

25. Marinoiu, A., Raceanu, M., Carcadea, E., Marinescu, D., Teodorescu, C., Mellichio, A., Varlam, M., Stefanescu, I. Convenient graphene Based Materials as Potential Candidates for Low Cost Fuel Cell Catalysts Reaction Kinetics, Mechanisms and Catalysis 118 2016: pp.281-296.

26. Kandlikar, S.G., Garofalo, M.L., Lu, Z. Water Management un A PEMFC: Water Transport Mechanism and Material Degradation un Gas Diffusion Layers Fuel Cells 11 (6) 2011: pp. 814-823. https://doi.org/10.1002/fuce.201000172

27. Simek, P., Klimova, K., Sedmidubsky, D., Janjovsky, O., Pumera, M., Sofer, Z. Towards Graphene Iodide: Iodination of Graphite Oxide Nanoscale 7 2015: pp. $261-270$.

28. Hassan, M., Haque, E., Minett, A.I., Gomes, V.G. CoDoping of Activated Graphene for Synergistically Enhanced Electrocatalytic Oxygen Reduction Reaction ChemSusChem 7-8 (23) 2015: pp. 4040-4048. 